\title{
Screening, Diagnosing and Prevention of Fetal Alcohol Syndrome: Is This Syndrome Treatable?
}

\author{
Sahar Ismail Stephanie Buckley Ross Budacki Ahmad Jabbar G. Ian Gallicano \\ Department of Biochemistry and Molecular and Cellular Biology, Georgetown University Medical Center, \\ Washington, D.C., USA
}

\section{Key Words}

Fetal alcohol syndrome $\cdot$ Fetal alcohol spectrum disorder • Prevention

\begin{abstract}
Prenatal alcohol exposure can lead to a wide range of adverse effects on a developing fetus. As a whole, these teratogenic outcomes are generally known as fetal alcohol spectrum disorders, the most severe of which is fetal alcohol syndrome (FAS). Clinically, children diagnosed with FAS vary greatly in their presentation of symptoms, likely due to the amount of alcohol and timing of exposure, as well as maternal and genetic influences. All these factors play a role in determining the mechanisms through which alcohol damages a developing brain, the details of which are still largely unknown. However, continuing research and recent developments have provided promising results that may lead to screening mechanisms and treatment therapies for children with FAS. Here we review the teratogenic effects of alcohol, strategies for detecting maternal alcohol consumption, identification of fetal biological markers, and prevention methods for FAS.

Copyright $\odot 2010$ S. Karger AG, Basel
\end{abstract}

\section{Introduction}

Fetal alcohol syndrome (FAS) in the USA occurs in rates ranging from 0.2 to 1.5 per 1,000 live births, depending on the populations studied and the surveillance methods used [Centers for Disease Control and Prevention, 2009]. This makes FAS one of the leading, known preventable causes of mental retardation and birth defects. Infants exposed to alcohol and diagnosed with FAS typically develop facial irregularities, central nervous system abnormalities and growth retardation [Missouri Department of Mental Health, 1994]. All women of reproductive age who are sexually active, not using effective birth control, and who consume alcohol are at a potential risk for having a child with FAS [Centers for Disease Control and Prevention, 2009].

FAS affects the baby, the family and the community as a whole. In a study of adverse adaptive behavioral problems of individuals diagnosed with FAS, five significant areas were noted through life history interviews with 415 patients. Of these individuals, $61 \%$ experienced disrupted school experiences, $60 \%$ noted some form of trouble with the law, 50\% reported an incidence of confinement defined as in jail, prison or psychiatric inpatient setting, $49 \%$ described repeated inappropriate sexual behaviors, and $35 \%$ reported alcohol and/or drug problems [Streiss-

G. Ian Gallicano, Georgetown University Medical Center

Department of Biochemistry and Molecular and Cellular Biology

3900 Reservoir Road, NW, Medical Dental Building, Room NE205

Washington, DC 20057 (USA)

Tel. +1 202687 0228, Fax +1 202687 1823, E-Mail gig@ georgetown.edu 
guth et al., 2004]. The report went on to note that children experienced a 2- to 4 -fold increased chance of escaping these five identified adverse life outcomes if diagnosed with FAS at an early age and reared in a good, stable environment [Streissguth et al., 2004]. As a result, it is of great importance to identify FAS at an early stage, so that the child may receive appropriate counseling and guidance throughout his/her life.

Based on the effects FAS creates on both the individual and the community, it is clear that FAS has become a vital area of research. Indeed, a robust amount of information has been discussed in the literature concerning FAS; however, a consensus has not been reached about prevention, identification of molecular markers for early detection, and potential treatments. Here, we pull together data from a number of investigations that have focused on the effects of alcohol as a teratogen, current screening and diagnostic tools, and identifying potential fetal biological markers. We also provide an overview of some potential courses of action for abrogating the harmful effects of alcohol during development.

\section{Alcohol as a Teratogen}

In order to develop clinical interventions for FAS, we must first understand how alcohol causes FAS. Alcohol is a drug capable of interfering with fetal development and causing birth defects - or, simply put, a teratogen [Kotch et al., 1995]. It is able to freely cross the placenta during pregnancy and enter the growing fetus through the umbilical cord [Centers for Disease Control and Prevention, 2009; Chernoff, 1977; Jones et al., 1973; Randall et al., 1977]. Depending on the amount and time of alcohol consumption during fetal development, certain developing tissues and organs may be seriously affected. The fetal brain in particular is highly susceptible because the degree of vascularization continually increases throughout gestation [Chang et al., 2003]. Thus, the brain may receive higher amounts of a teratogen as development continues, making the developing central nervous system particularly vulnerable to the teratogenic effects of alcohol [Swayze et al., 1997].

The risk for alcohol-related birth defects increases due to the interactions of a variety of factors (fig. 1). These factors include increased maternal age, parity, history of alcohol abuse, poverty, smoking and drug use, nutritional deficiencies and poor prenatal care [Abel and Hannigan, 1995; McCarver etal., 1997]. In addition, genetic influences have also been shown to increase or decrease the suscep- tibility to alcohol teratogenesis. For instance, women with a more efficient alcohol dehydrogenase enzyme (ADH) and cytochrome P450 2E1 have a decreased risk for giving birth to a child with FAS [McCarver et al., 1997; McCarver, 2001]. In terms of alcohol metabolism, class I ADH is the most important class of human ADH. Absence of $\mathrm{ADH} 2$, which encodes the $\beta$-subunit of class I ADH isoenzymes, has been shown to leave the child at a higher risk for alcohol-related birth deficits [McCarver et al., 1997].

Early detection of FAS is necessary since proper care early in a child's life can reduce the severity of impairments. However, early detection is difficult because it relies solely on physical appearance and nervous system abnormities, which can be highly variable [Datta et al., 2008]. The hallmark of FAS is the array of craniofacial abnormalities. Children with FAS can display a mixture of dysmorphic facial features, which include a long flat philtrum, low nasal bridge, short palpebral fissures, thin upper lip, ear malformations, flattened maxilla, short upturned nose, and epicanthal folds (fig. 2) [Astley et al., 1992; Kvigne et al., 2004]. Ethanol has been shown to induce these craniofacial anomalies in part by interfering with neural crest maintenance and migration [Brown et al., 1979]. Ethanol can induce cell damage by increasing reactive oxygen intermediates such as superoxide, hydrogen peroxide and hydroxyl anions [Davis et al., 1990]. The exact mechanisms remain unknown, but the addition of the free radical scavenging enzyme superoxide dismutase has been shown to significantly reverse the effects of ethanol in vitro [Amini et al., 2009; Davis et al., 1990]. Using antioxidants, these anomalies have been partially reversed in vivo, implying that oxidative stress plays a partial role in their development [Cano et al., 2001; Peng et al., 2005; Reimers et al., 2006].

Other clinical presentations seen in FAS are nervous system abnormalities, which include developmental delay, microcephaly, seizures, hyperactivity, attention deficits, cognitive deficits, learning and memory impairments, poor psychosocial functioning and motor coordination deficits [Kvigne et al., 2004]. Of the most prevalent processes particularly damaged by alcohol are those that regulate neurodevelopmental processes, specifically the development of the neural tube, corpus callosum, cerebellum and brainstem (fig. 3) [Dunty et al., 2001; Moreland et al., 2002; Swayze et al., 1997]. Agenesis of these structures leads to the cognitive and physical dysfunction observed in FAS patients. Currently, several studies using both in vitro and in vivo rodent models highlight the significant, yet variable, effects of alcohol on neurogenesis. Camarillo et al. [2007] observed a reduction in stem cell 
Fig. 1. Summary of the interactions of maternal risk factors and mechanisms related to FAS and alcohol-related birth defects (ARBDs). Sociobehavioral factors are listed inside circles and include alcohol intake pattern, low socioeconomic status (low SES), culture and smoking. Biological factors are listed inside squares and include blood alcohol levels, tobacco components, undernutrition, free radicals, hypoxia and cell damage. Solid lines: biological relationships and physiological pathways. Dotted lines: interactions among environmental and behavioral factors. GI = Gastrointestinal [Abel and Hannigan, 1995; by permission of Elsevier Inc.].

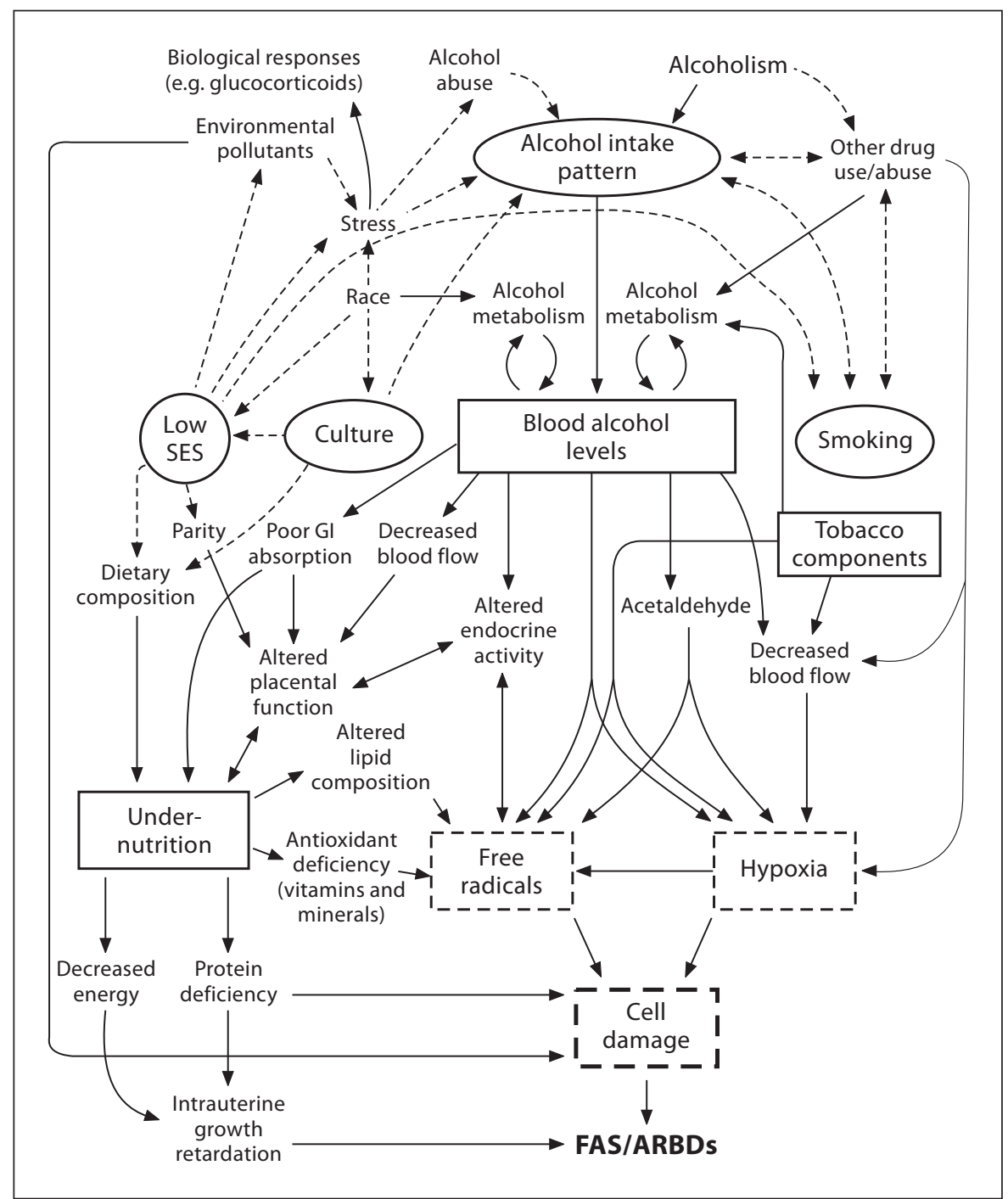

number, increase in neuronal proliferation, decreased genomic stability and delayed neuronal differentiation. Further research showed that these changes were in part due to the effect of ethanol on cytokine release. Ethanol disrupts the release of cytokines, which propel angiogenesis and neural growth [Camarillo et al., 2007]. Ethanol exposure during neurogenesis also increased the expression of genes involved in neuronal migration and suppressed growth-associated proteins [Camarillo et al., 2008]. They observed reduced neurite branching and increased primary neurite length in ethanol-pretreated differentiating neurons in the proliferative phase [Camarillo et al., 2008]. Most recently, Singh et al. [2009] described several molecular changes in neurogenesis found in embryonic rodents exposed to alcohol. The focus of the study was on Wnt- $\beta$-catenin and its role in ethanol-induced changes in neurogenesis. They found differences in the Wnt- $\beta$-catenin signaling pathway alongside changes in cytosolic calcium concentrations. Wnt signaling is an important regulator of stem cell self-renewal in the developing brain. It is required for proper cloning and expansion of stem cells, and for proper neural stem cell function throughout one's lifetime [Lie et al., 2005; Wexler et al., 2009]. Moreover, there was a GABAergic upregulation, which may lead to abnormal synapse maturation and/or increase in neuronal apoptosis.

Alcohol also has been shown to affect neurotransmitter pathways, such as the serotonergic 5-hydroxytryptamine (HT) pathway, by reducing the number and density of 5-HT neurons in the developing embryo [Sari and 
Fig. 2. Facial characteristics of 10 patients with FAS. a Images of patients 1-10. Top row: patients 1-5. Bottom row: patients 6-10. b List of dysmorphic craniofacial features displayed by patients 1-10 [Swayze et al., 1997; by permission of the American Academy of Pediatrics].
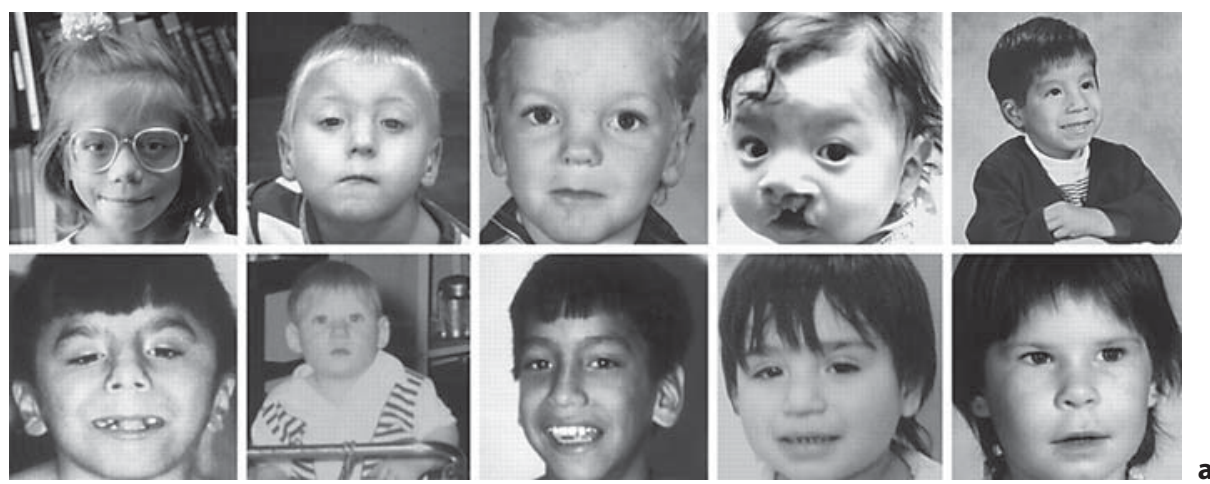

\begin{tabular}{|c|c|c|c|c|c|c|c|c|c|c|}
\hline \multirow[t]{2}{*}{ Feature } & \multicolumn{10}{|c|}{ Patient, No. } \\
\hline & 1 & 2 & 3 & 4 & 5 & 6 & 7 & 8 & 9 & 10 \\
\hline Small chin & $\mathrm{Y}$ & $\mathrm{Y}$ & $\ldots$ & Y & Y & $\mathrm{Y}$ & $\ldots$ & Y & $\ldots$ & $\ldots$ \\
\hline Cleft palate/cleft lip & $\ldots$ & $\ldots$ & $\ldots$ & $\mathrm{Y}$ & $\mathrm{Y}$ & $\mathrm{Y}$ & $\ldots$ & $\ldots$ & $\ldots$ & $\ldots$ \\
\hline Low nasal bridge & $\mathrm{Y}$ & $\mathrm{Y}$ & $\mathrm{Y}$ & Y & Y & $\ldots$ & Y & $\ldots$ & $\ldots$ & $\ldots$ \\
\hline Hypoplastic maxillae & $\mathrm{Y}$ & $\mathrm{Y}$ & $\mathrm{Y}$ & $\mathrm{Y}$ & $\mathrm{Y}$ & $\mathrm{Y}$ & $\mathrm{Y}$ & $\mathrm{Y}$ & $\ldots$ & $\ldots$ \\
\hline Ptosis & $\mathrm{Y}$ & $\mathrm{Y}$ & $\ldots$ & $\ldots$ & $\ldots$ & $\mathrm{Y}$ & $\mathrm{Y}$ & $\ldots$ & $\mathrm{Y}$ & $\ldots$ \\
\hline Apparent hypertelorism & $\mathrm{Y}$ & $\mathrm{Y}$ & $\mathrm{Y}$ & $\mathrm{Y}$ & $\ldots$ & $\mathrm{Y}$ & $\ldots$ & $\ldots$ & $\ldots$ & $\ldots$ \\
\hline Narrow palpebral fissure & $\mathrm{Y}$ & $\mathrm{Y}$ & $\mathrm{Y}$ & Y & $\mathrm{Y}$ & $\mathrm{Y}$ & $\mathrm{Y}$ & $\ldots$ & $\mathrm{Y}$ & $\mathrm{Y}$ \\
\hline Epicanthic folds & $\ldots$ & $\ldots$ & $\mathrm{Y}$ & Y & Y & $\mathrm{Y}$ & $\mathrm{Y}$ & $\ldots$ & $\ldots$ & $\mathrm{Y}$ \\
\hline Short nose/anteverted nostrils & $\ldots$ & $\mathrm{Y}$ & Y & $\ldots$ & $\ldots$ & $\mathrm{Y}$ & $\ldots$ & $\ldots$ & $\ldots$ & $\mathrm{Y}$ \\
\hline Thin upper lip & $\mathrm{Y}$ & $\mathrm{Y}$ & Y & Y & $\mathrm{Y}$ & $\mathrm{Y}$ & Y & Y & $\ldots$ & Y \\
\hline Smooth and/or long philtrum & $\ldots$ & $\mathrm{Y}$ & $\mathrm{Y}$ & $\ldots$ & $\mathrm{Y}$ & $\mathrm{Y}$ & $\ldots$ & $\mathrm{Y}$ & $\mathrm{Y}$ & $\mathrm{Y}$ \\
\hline
\end{tabular}

Zhou, 2004]. The lack of 5-HT neurons has been suggested as a contribution to the abnormal development of the central nervous system in FAS [Zhou et al., 2002]. MR imaging has been used to visualize some of these effects, which include reductions in the anterior cerebellar vermis and basal ganglia, as well as a narrowing of and increased gray matter density in certain regions of the association cortex [Swayze et al., 1997]. Unfortunately, a broad range of these symptoms are observed at varying degrees of severity and in various combinations, making it difficult for clinicians to diagnose children with FAS.

The term 'fetal alcohol spectrum disorders' (FASD) is used to describe the range of effects that can occur in an individual born to a mother who consumed alcohol during pregnancy. These effects may include any of the physical, mental, behavioral and/or learning disabilities already described. The term FASD is not intended for use as a clinical diagnosis. However, to diagnose a child with FAS, the child must have all three findings: three facial abnormalities, growth deficits and central nervous system abnormalities [Centers for Disease Control and Prevention, 2009]. Consequently, children not meeting these diagnostic criteria are missed. Future research designed to find ethanol-induced gene expression alterations, as well as elucidating these mechanisms, will be important not only to help physicians diagnose and prevent FAS, but to reverse the physical and neurological consequences of alcohol using in utero or postnatal treatments.

\section{Fetal Biological Markers}

Since an early stage diagnosis in the clinical setting is the key to reaching better outcomes in life, more research is required to obtain the necessary diagnostic tools. One promising, albeit challenging, method of early FAS diagnosis is analyzing the levels of fatty acid ethyl esters (FAEE) in the meconium. The fetus metabolizes alcohol producing FAEE, which can be detected in the meconium, the first stool passed by the infant usually in the first $72 \mathrm{~h}$ [Bearer et al., 2005]. While FAEE levels appear to be increased in newborns exposed to alcohol in utero [Bearer et al., 2005], further investigation is needed to determine whether infants with high FAEE levels in the meconium are at high risk for developmental abnormalities. In addition, the meconium is produced only in the later part 


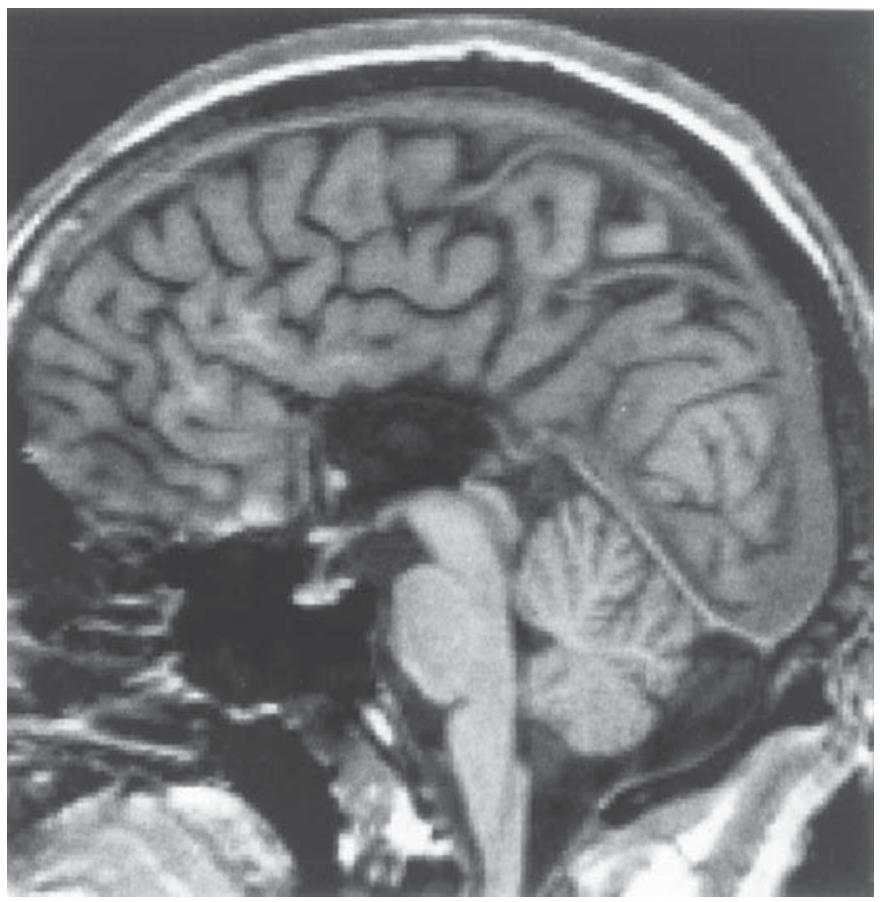

Fig. 3. MR image of 26-year-old male patient with FAS. Complete agenesis of the corpus callosum and hippocampal commissure [Swayze et al., 1997; by permission of the American Academy of Pediatrics].

of pregnancy, which does not help in identifying infants exposed to alcohol in only the earlier part of pregnancy [Bearer et al., 2005]. As a result, additional studies and markers are needed to better determine the specificity and sensitivity of this relatively new methodology.

The use of fetal biological markers could aid in the early detection of children with FAS. This early diagnosis could allow for appropriate measures to be taken in order to support and assist the child and family in regard to education and social development. In addition to early diagnosis, fetal biological markers can be used to more thoroughly understand the pathogenesis of FAS. Several genetic studies have already been undertaken to elucidate the mechanisms involved in the changes that occur during fetal alcohol exposure. Hard et al. [2005] investigated ethanol-induced alterations in gene expression in the fetal brain using complementary DNA microarrays. They identified 25 genes that are involved in cell proliferation, differentiation and apoptosis, and contribute to tissue growth and remodeling as well as to neuronal growth and survival [Hard et al., 2005]. Using real-time PCR analysis, Vangipuram et al. [2008] further showed that alcohol significantly altered the expression of genes involved in cell adhesion. We found that these genetic studies could be grouped into specific categories including cell migration, apoptosis, cellular growth, cell adhesion molecules and microRNA.

\section{Cell Migration}

One of the processes hypothesized to be interrupted in fetal brains exposed to ethanol is cell migration. In the nervous system, proteolysis of the extracellular matrix (ECM) plays a role in the migration of neuronal cells in the developing cerebellum, and in neurite outgrowth [Vaillant et al., 1999; Chambaut-Guerin et al., 2000]. ECM degradation is under the control of matrix metalloproteases (MMP), while tissue-derived inhibitors of metalloproteases regulate the activity of MMP. Tissuederived inhibitors of metalloproteases were found to be downregulated as a result of ethanol [Hard et al., 2005]. As a result, removing MMP inhibition results in more ECM breakdown and disregulation of neuronal cell migration. Interestingly, while there seems to be a relatively rich array of work in this area on adult neuronal malfunction [Haorah et al., 2008], there seems to be a void in cellmigration/alcohol-related research during development. Cuzon et al. [2008] make this point, albeit indirectly, in their thorough investigation of GABAergic interneuron mismigration during mouse development. However, it is attractive to speculate that alcohol (ethanol) could be a useful tool in future experiments for following neuronal cell migration fates in various mouse embryonic models that have transgenic reporter genes. A mouse model containing two transgenes, such as a specific neural promoter driving green fluorescent protein and a glial promoter driving red fluorescent protein, could be used to follow each cell type during cell migration in response to alcohol. Such experiments could help answer why and how alcohol functions to induce neural problems.

\section{Apoptosis}

Ubiquitylation, a process by which proteins are targeted for proteolysis, plays an important role in many cellular functions including apoptosis, cell cycle regulation, and differentiation [Hard et al., 2005]. Rnf25, a gene involved in ubiquitylation, is downregulated in prenatal alcohol-exposed mice [Lorick et al., 1999; Hard et al., 2005]. Also found downregulated in fetal brains exposed to ethanol is TUSP (Tulp4), a member of the tubby-gene family, mainly expressed in the brain [Li et al., 2001]. It is believed that Tulp may have several diverse functions including transcription, vesicular trafficking and involvement in the insulin-signaling pathway and apoptosis 
[Hard et al., 2005; Kong et al., 2009]. Therefore, downregulation of this gene, as seen in alcohol-exposed fetuses, could result in neuronal cell death.

More canonical pathways such as the Ras pathway have also been shown to be affected by alcohol. Ras proteins are a family of guanosine-diphosphate- and guanosine-5'-triphosphate-binding proteins that are involved in signal transduction pathways that mediate differentiation, proliferation and apoptosis [Scita et al., 2000]. Altered levels of active Ras and mutating Ras proteins have been associated with teratogenicity and tumorigenesis, respectively [Winn and Wells, 2002; Suvarna et al., 2005].

\section{Cellular Growth and Differentiation}

Serine/threonine protein kinases, which mediate signal transduction processes, affect a range of cellular processes such as insulin response, cell growth, regulation of apoptotic proteins, and transcription factors [Lawlor and Alessi, 2001]. Akt, a serine/threonine protein kinase, is downregulated, disrupting normal cell growth and impairing normal cell survival [Hard et al., 2005; Scanga et al., 2000; Verdu et al., 1999]. The Akt gene is involved in the phosphoinositide-3 kinase signaling pathway, which participates in the development of the central nervous system by promoting neuronal and glial survival and differentiation [Dudek et al., 1997].

Another known gene involved in cell growth found to be downregulated in fetal brains exposed to ethanol is Dexras1 [Hard et al., 2005]. It is believed that Dexras1 is a target of neuronal nitric oxide (NO) synthase and is an effector of NO signaling [Fang et al., 2000]. Decreases in neuronal NO synthase limit brain growth, as seen in prenatal alcohol exposure.

One elegant study that must be noted evaluated the levels of phosphorylated cyclic adenosine monophosphate response element of binding protein (pCREB) staining in hippocampal subregions of alcohol-treated pregnant mice [Roberson et al., 2009]. Hippocampal CREB activity is believed to be important for long-term memory formation and hippocampus-dependent learning. It has been shown that the cyclic adenosine monophosphate-CREB cascade plays an important role in the differentiation and maturation of neurons during hippocampal neurogenesis. This study found that in utero alcohol exposure decreased pCREB activity in hippocampal subregions of adult mice, with the greatest decline in the dentate gyrus. This suggests FAS adult learning deficits may correlate to increased dentate gyrus neurodegeneration. pCREB, in addition to other markers, can be used to diagnose FAS.

\section{Cell Adhesion Molecules}

A recent, very interesting study by Vangipuram et al. [2008] investigated the effects of alcohol on fetal human brain-derived neural progenitor cells. Using real-time PCR analysis, they showed that alcohol significantly altered the expression of genes involved in cell adhesion. An increase in the expressions of $\alpha$-laminin-1, collagen type $4 \alpha$-2, $\beta$-laminins $1, \beta$-integrins 3 and 5 , secreted phosphoprotein 1 , and sarcoglycan epsilon were prevalent. Alcohol had no effect on neural progenitor cell apoptosis but resulted in a more rapid coalescence and increased volume of neurospheres. The changes in cell adhesion found in this study may play an additional role in the neurodevelopmental defects associated with FAS.

Since all the genes identified are involved in cell proliferation, differentiation and apoptosis, and contribute to tissue growth and remodeling as well as neuronal growth and survival, downregulation of these genes - as seen with FAS - can have major consequences on fetal development. Measuring the levels of these essential genes can serve as a tool to identify infants with FAS.

\section{MicroRNA Expression}

MicroRNA expression can also be used as a tool to identify FAS. MicroRNA are small noncoding sequences of mRNA that complementarily bind to RNA and regulate its translation [Foshay and Gallicano, 2009; Houbaviy et al., 2003; Krichevsky et al., 2006; Wang et al., 2009]. The study done by Wang et al. [2009] explored microRNA expression patterns during FAS/alcohol-related neurodevelopmental disorder. They found that the microRNA miR-10a, miR-10b, miR-9, miR-145, miR-30a-3p and miR-152 were upregulated in fetal brains with prenatal alcohol exposure, whereas miR-200a, miR-496, miR296, miR-30e-5p, miR-362, miR-339, miR-29c and miR154 were downregulated [Wang et al., 2009]. miR-10a is clustered with Hox genes, which are known to play an important role in embryonic development. Further investigation showed that unregulated miR-10a is associated with inhibition of the hoxal gene in prenatal alcohol exposure models. They also found that alcohol- and folicacid-treated mice showed no change in Hoxal expression, suggesting that the fetal alcohol supplementation was protective for the ethanol-exposed mice [Wang et al., 2009]. It is becoming evident that a panel of genes and microRNA may be a potentially powerful clinical diagnostic tool for FAS. Numerous investigations are exploring this approach. Unfortunately, the tools available in the clinic are limited and are used primarily for determining the risk of developing FAS. 


\section{Detecting Maternal Alcohol Consumption}

Screening is currently seen as the most effective way to detect alcohol use during pregnancy. Administering questionnaires have been shown to at least help determine if a mother is at risk and in need of further evaluation [Bradley et al., 1998]. However, while questionnaires are helpful, the identification of biological markers provides a different, more empirical method for detecting FAS. The most obvious method for detecting acute alcohol ingestion can be revealed by using blood, urine or exhaled air markers. Breath alcohol provides an immediate indication of alcohol use, while blood and urine are used to detect alcohol only a few hours after consumption. However, these methods require testing of the mother on a routine basis, which can be difficult. In contrast, markers that reflect nonacute alcohol abuse are determined through the objective analysis of biochemical markers reflective of the changes or damage caused by alcohol or its metabolites [Stoler et al., 1998].

Indirect detection of chronic alcohol abuse can be identified through hemoglobin-associated acetaldehyde, $\gamma$-glutamyltransferase, mean corpuscular volume and carbohydrate-deficient transferrin [Chalmers et al., 1979; Conigrave et al., 2002; Hazelett et al., 1998; Niemela et al., 1990; Stoler et al., 1998]. As products involved in either alcohol metabolism or alcohol-induced organ damage, these markers may be used to determine alcohol abuse in pregnant women. To date, it appears that there are variations in the diagnostic efficacy of these markers in various studies [Conigrave et al., 2002; Hazelett et al., 1998; Hock et al., 2005; Nyström et al., 1992]. The diagnostic sensitivity of each carbohydrate-deficient transferrin, $\gamma$-glutamyltransferase, and mean corpuscular volume is increased when used as a panel rather than individually [Stoler et al., 1998; Reynaud et al., 2000]. It has been shown that infants born to mothers having $\geq 2$ positive markers had significantly smaller birth weights, lengths and head circumferences than infants born to mothers who were negative for all the markers [Stoler et al., 1998]. However, the effects of alcohol on the developing fetus are variable. Alcohol ingestion does not necessarily result in FAS, therefore current methods of alcohol screening and at-birth examination of the physical features associated with FAS are not effective diagnostic tools.

More recently, a study by Datta et al. [2008] attempted to find biomarkers of high sensitivity in amniotic fluid (AF). They specifically looked at how the protein complexity of the AF changes in association with the risk for alcohol-related birth defects. A murine model was used to screen AF for biomarkers that could potentially discriminate between FAS-positive and FAS-negative pregnancies. Preliminary screening of AF peptides revealed a significant difference between high-risk pregnancies and low-risk pregnancies. With the use of MALDI-TOF mass spectroscopy analysis, three peaks were found to be reduced in the FAS positive. Of the three peaks, two were identified as corresponding to $\alpha$-fetoprotein (AFP). They concluded that reductions in AFP could eventually be used as a clinical diagnostic. Their study, in essence, confirmed and advanced the results of an older study in which FAS was predicted correctly in $59 \%$ of pregnancies with low maternal serum AFP [Halmesmaki et al., 1987]. Although we can say that there is ongoing research to find a biological marker within the fetus to distinctively diagnose FAS, we found it surprising that the literature was not swamped with investigations and ideas. This is a fact that needs to be accentuated if a concerted effort is to be made to put a dent in treating or even curing FAS.

\section{Prevention of FAS}

Since so much is unknown about the exact mechanisms through which alcohol acts as a teratogen, the Centres of Disease Control and Prevention (CDC) recommend that there is no safe period of time during pregnancy to consume alcohol and that women who are considering becoming pregnant, who are at risk for becoming pregnant or who are pregnant abstain from alcohol consumption [Centers for Disease Control and Prevention, 2009]. On the other hand, mixed results have been reported on the effects of alcohol during the prenatal period in mice, corresponding to human organogenesis [Becker et al., 1989; Downing et al., 2009; Middaugh et al., 1988; Mothes et al., 1996]. Consensus suggests that it is the initial few days of mouse postnatal growth, corresponding to the first 2-3 weeks of the human brain growth spurt, which dictate the period when the effects of alcohol are detrimental. However, only so much can be concluded about humans from mouse studies, and alcohol may have detrimental effects at any time during brain development; therefore, at this time, it is better to err on the side of caution and assume that alcohol consumed at any time during pregnancy can be a potential threat to the developing fetus.

Indeed, prevention of FAS is an important goal primarily because so little is understood with regard to the adverse effects that alcohol has on the developing fetus. 
The CDC have a number of current prevention plans aimed at educating the potential mothers at risk for conceiving a child with FAS. These projects include the Changing High-Risk Alcohol Use and Increasing Contraception Effectiveness Study (CHOICES) and the Birth Control and Alcohol Awareness: Negotiating Choices Effectively (BALANCE) project [Centers for Disease Control and Prevention, 2009]. These prevention plans revolve around the goal of providing education about effective birth control methods and the risks of alcohol use [Centers for Disease Control and Prevention, 2009].

However, educational resources can only go so far in the prevention of FAS. A potentially more powerful means for preventing the effects of FAS is to provide protection to the developing neurotransmitter pathways early on in pregnancy. This protection could block the harmful effects of alcohol consumed during early pregnancy when the pregnancy was not yet known.

It is believed that serotonin agonists $\left(5-\mathrm{HT}_{1 \mathrm{~A}}\right)$ such as buspirone or ipsapirone could be used as therapeutic compounds for the treatment of brain malformations caused by prenatal ethanol exposure [Eriksen and Druse, 2001]. In FAS, a delayed closing of the neural tube is noted, which is characterized as incomplete dysraphia [Zhou et al., 2008]. Another possible agent for the prevention of the effects of FAS are neuroprotective peptides, whose intervention capabilities are currently being studied in animal models. One peptide, with the sequence NAPVSIPQ (NAP), is a fragment of the activity-dependent neuroprotective protein [Spong et al., 2001]. Another peptide, with the sequence SALLRSIPA (SAL), is a fragment of the activity-dependent neurotrophic factor [Spong et al., 2001]. Both NAP and SAL have been shown to provide protective intervention in a model of FAS [Spong et al., 2001]. Activity-dependent neurotrophic factor release from astroglia is stimulated by vasoactive intestinal peptides and protects cells from apoptosis associated with electrical blockade [Gozes et al., 1999]. Treatment with NAP alone was shown to be effective at preventing ethanol-induced fetal death, while SAL infusion alone was not shown to be effective [Spong et al., 2001]. However, treatment with both peptides was necessary to prevent the growth restriction, in addition to the prevention of alcohol-induced fetal death produced by prenatal alcohol treatment [Spong et al., 2001]. The copeptide administration was effective even $1 \mathrm{~h}$ after ethanol treatment. On the other hand, if the treatment was delayed for $3 \mathrm{~h}$ after ethanol treatment, no neuroprotective effect was noted [Spong et al., 2001]. This suggests that after a certain period, irreversible damage to the embryo will occur from ethanol toxicity, but the long-term protection from damage can be facilitated by the administration of both the NAP and SAL peptides concurrently before and during alcohol exposure [Spong et al., 2001]. The mechanism by which the peptides NAP and SAL provide neuroprotection is not clear. They may be providing a direct protection mechanism for $5-\mathrm{HT}$ or an earlier protection of neurulation. When these investigations are brought together, a pattern emerges that points to a potentially exciting method for the prevention of FAS. Clearly, more research needs to be implemented on the underlying mechanism of action based on which the peptides provide protection.

\section{Conclusion}

As a teratogen, alcohol affects many aspects of fetal development. Although it is still unclear what exactly the molecular mechanisms are through which alcohol acts and interferes with normal fetal development, it is clear that the results can be dramatic and irreversible. In the case of FAS in particular, alcohol affects brain development in a manner that leads to both inhibited cognitive and behavioral function. It also leads to stunted growth development and abnormal facial features [Missouri Department of Mental Health, 1994]. All of these factors combine to make life difficult for both patients and their families. This is why the CDC recommend that no alcohol be consumed at any time during pregnancy [Centers for Disease Control and Prevention, 2009].

Currently, physicians rely heavily on history-taking to screen for women at high risk of alcohol consumption during pregnancies [Cook, 2003]. However, these screenings are not enough since patients are reluctant to admit the amount of alcohol they consume and physicians are reluctant to talk about it with patients. The use of questionnaires is also only effective to a limit. Therefore, the aim of scientists and physicians is to devise more effective screening methods.

A panel of several markers have been studied that test for alcohol consumption during pregnancy and serve as a tool to look at risky behavior and attempt to prevent further damage to the fetus. However, these markers reflect alcohol ingestion in the mother, but do not diagnose a fetus with FAS. Consequently, specific markers in the infant are also needed to confirm a diagnosis at an early stage. In fact, many genes necessary for cell differentiation, apoptosis, neuronal cell adhesion and development have been found to be altered in FAS. These genes serve 
as potential and promising markers for diagnosing FAS. To date, research efforts into FAS have yet to overcome many challenges, but it appears that headway is being made in understanding FAS and potentially finding relevant treatments and cures.

\section{Acknowledgments}

We would like to thank Dr. Peggy Weissinger, Dr. Stephen Ray Mitchell and Dr. Shyrl Sistrunk for their time and effort with this manuscript. We would also like to thank Tammy Gallicano for editorial comments.

\section{References}

Abel EL, Hannigan JH (1995): Maternal risk factors in fetal alcohol syndrome: provocative and permissive influences. Neurotoxicol Teratol 17:448-462.

-Amini S, Merabova N, Khalili K, Darbinian N (2009): p38SJ, a novel DINGG protein, protects neuronal cells from alcohol-induced injury and death. J Cell Physiol 221:499-504.

-Astley SJ, Clarren SK, Little RE, Sampson PD, Daling JR (1992): Analysis of facial shape in children gestationally exposed to marijuana, alcohol, and/or cocaine. Pediatrics 89:67-77.

- Bearer CF, Santiago LM, O'Riordan MA, Buck K, Lee SC, Singer LT (2005): Fatty acid ethyl esters: quantitative biomarkers for maternal alcohol consumption. J Pediatr 146:824-830.

Becker HC, Randall CL (1989): Effects of prenatal ethanol exposure in C57BL mice on locomotor activity and passive avoidance behavior. Psychopharmacology (Berl) 97:40-44.

-Bradley KA, Boyd-Wickizer J, Powell SH, Burman ML (1998): Alcohol screening questionnaires in women: a critical review. JAMA 280:166-171.

Brown NA, Goulding EH, Fabro S (1979): Ethanol embryotoxicity: direct effects on mammalian embryos in vitro. Science 260:573575.

Camarillo C, Kumar LS, Bake S, Sohrabji F, Miranda RC (2007): Ethanol regulates angiogenic cytokines during neural development: evidence from an in vitro model of mitogenwithdrawal-induced cerebral cortical neuroepithelial differentiation. Alcohol Clin Exp Res 31:324-335.

-Camarillo C, Miranda RC (2008): Ethanol exposure during neurogenesis induces persistent effects on neural maturation: evidence from an ex vivo model of fetal cerebral cortical neuroepithelial progenitor maturation. Gene Expr 14:159-171.

- Cano MJ, Ayala A, Murillo ML, Carreras O (2001): Protective effect of folic acid against oxidative stress produced in 21-day postpartum rats by maternal-ethanol chronic consumption during pregnancy and lactation period. Free Radic Res 34:1-8.

Centers for Disease Control and Prevention (2009): National Center on Birth Defects and Developmental Disabilities. http://www.cdc. gov/ncbddd (accessed August 24, 2009).
Chalmers DM, Levi AJ, Chanarin I, North WR, Meade TW (1979): Mean cell volume in a working population: the effects of age, smoking, alcohol, and oral contraception. $\mathrm{Br} \mathrm{J}$ Haematol 43:631-636.

Chambaut-Guérin AM, Hérigault S, Rouet-Benzineb P, Rouher C, Lafuma C (2000): Induction of matrix metalloproteinase MMP-9 (92-kDa gelatinase) by retinoic acid in human neuroblastoma SKNBE cells: relevance to neuronal differentiation. J Neurochem 74: 508-517.

Chang C, Yu C, Ko H, Chen C, Chang F (2003): Three-dimensional power Doppler ultrasound for the assessment of the fetal brain blood flow in normal gestation. Ultrasound Med Biol 29:1273-1279.

Chernoff GF (1977): The fetal alcohol syndrome in mice: an animal model. Teratology 15: 223-229.

Conigrave KM, Degenhardt LJ, Whitfield JB, Saunders JB, Helander A, Tabakoff B (2002): CDT, GGT, and AST as markers of alcohol use: the WHO/ISBRA collaborative project. Alcohol Clin Exp Res 26:332-339.

Cook JD (2003): Biochemical markers of alcohol use in pregnant women. Clin Biochem 36 9-19.

Cuzon VC, Yeh PW, Yanagawa Y, Obata K, Yeh HH (2008): Ethanol consumption during early pregnancy alters the disposition of tangentially migrating GABAergic interneurons in the fetal cortex. J Neurosci 28:1854-1864.

Datta S, Turner D, Singh R, Ruest LB, Pierce WM Jr, Knudsen TB (2008): Fetal alcohol syndrome (FAS) in C57BL/6 mice detected through proteomics screening of the amniotic fluid. Birth Defects Res A Clin Mol Teratol 82:177-186.

-Davis WL, Crawford LA, Cooper OJ, Farmer GR Thomas DL, Freeman BL (1990): Ethanol induces the generation of reactive free radicals by neural crest cells in vitro. J Craniofac Genet Dev Biol 10:277-293.

Downing C, Balderrama-Durbin C, Hayes J, Johnson TE, Gilliam D (2009): No effect of prenatal alcohol exposure on activity in three inbred strains of mice. Alcohol Alcohol 44:25-33.

Dudek H, Datta SR, Franke TF, Birnbaum MJ, Yao R, Cooper GM, Segal RA, Kaplan DR, Greenberg ME (1997): Regulation of neuronal survival by the serine-threonine protein kinase Akt. Science 275:661-665.
Dunty WC Jr, Chen SY, Zucker RM, Dehart DB, Sulik KK (2001): Selective vulnerability of embryonic cell populations to ethanol-induced apoptosis: implications for alcoholrelated birth defects and neurodevelopmental disorder. Alcohol Clin Exp Res 25: 1523-1535.

-Eriksen JL, Druse MJ (2001): Astrocyte-mediated trophic support of developing serotonin neurons: effects of ethanol, buspirone, and S100B. Dev Brain Res 131:9-15.

-Fang M, Jaffrey SR, Sawa A, Ye K, Luo X, Snyder SH (2000): Dexras1: a G protein specifically coupled to neuronal nitric oxide synthase via CAPON. Neuron 28:183-193.

-Foshay KM, Gallicano GI (2009): miR-17 family miRNAs are expressed during early mammalian development and regulate stem cell differentiation. Dev Biol 326:431-443.

-Gozes I, Bassan M, Zamostiano R, Pinhasov A, Davidson A, Giladi E, Perl O, Glazner GW, Brenneman DC (1999): A novel signaling molecule for neuropeptide action: activitydependent neuroprotective protein. Ann NY Acad Sci 897:125-135.

Halmesmäki E, Autti I, Granström ML, Heikinheimo M, Raivio KO, Ylikorkala O (1987): Prediction of fetal alcohol syndrome by maternal $\alpha$-fetoprotein, human placental lactogen and pregnancy specific $\beta_{1}$-glycoprotein. Alcohol Alcohol Suppl 1:473-476.

Haorah J, Ramirez SH, Floreani N, Gorantla S, Morsey B, Persidsky Y (2008): Mechanism of alcohol-induced oxidative stress and neuronal injury. Free Radic Biol Med 45:1542-1550.

- Hard ML, Abdolell M, Robinson BH, Koren G (2005): Gene-expression analysis after alcohol exposure in the developing mouse. J Lab Clin Med 145:47-54.

-Hazelett SE, Liebelt RA, Brown WJ, Androulakakis V, Arjoura D, Truitt EB (1998): Evaluation of acetaldehyde-modified hemoglobin and other markers of chronic heavy alcohol use: effects of gender and hemoglobin concentration. Alcohol Clin Exp Res 22:1813-1819.

Hock B, Schwarz M, Domke I, Grunert VP, Wuertemberger M, Schiemann U (2005): Validity of carbohydrate-deficient transferrin $(\% \mathrm{CDT}), \gamma$-glutamyltransferase $(\gamma$-GT) and mean corpuscular erythrocyte volume (MCV) as biomarkers for chronic alcohol abuse: a study in patients with alcohol dependence and liver disorders of non-alcoholic and alcoholic origin. Addiction 100:1477-1486. 
Houbaviy HB, Murray MF, Sharp PA (2003): Embryonic stem cell-specific MicroRNAs. Dev Cell 5:351-358.

Jones KL, Smith DW, Ulleland CN, Streissguth AP (1973): Pattern of malformation in offspring of chronic alcoholic mothers. Lancet i:1267-1271.

Kong L, Chen GD, Zhou X, McGinnis JF, Li F, Cao W (2009): Molecular mechanisms underlying cochlear degeneration in the tubby mouse and the therapeutic effect of sulforaphane. Neurochem Int 54:172-179.

Kotch LE, Chen SY, Sulik KK (1995): Ethanolinduced teratogenesis: free radical damage as a possible mechanism. Teratology 52:128136.

Krichevsky AM, Sonntag KC, Isacson O, Kosik KS (2006): Specific microRNAs modulate embryonic stem cell-derived neurogenesis. Stem Cells 24:857-864.

Kvigne VL, Leonardson GR, Neff-Smith M, Brock E, Borzelleca J (2004): Characteristics of children who have full or incomplete fetal alcohol syndrome. J Pediatr 145:635-640.

-Lawlor MA, Alessi DR (2001): PKB/Akt: a key mediator of cell proliferation, survival and insulin responses? J Cell Sci 114:2903-2910.

- Li QZ, Wang CY, Shi JD, Ruan QG, Eckenrode S, Davoodi-Semiromi A, et al (2001): Molecular cloning and characterization of the mouse and human TUSP gene, a novel member of the tubby superfamily. Gene 273:275284

- Lie DC, Colamarino SA, Song HJ, Désiré L, Mira $\mathrm{H}$, Consiglio A (2005): Wnt signalling regulates adult hippocampal neurogenesis. $\mathrm{Na}$ ture 437:1370-1375.

Lorick KL, Jensen JP, Fang S, Ong AM, Hatakeyama S, Weissman AM (1999): RING fingers mediate ubiquitin-conjugating enzyme (E2)-dependent ubiquitination. Proc Natl Acad Sci USA 96:11364-11369.

-McCarver (2001): ADH2 and CYP2E1 genetic polymorphisms: risk factors for alcohol-related birth defects. Drug Metab Dispos 29: 562-565.

-McCarver DG, Thomasson HR, Martier SS, Sokol RJ, Li T (1997): Alcohol dehydrogenase- $2 * 3$ allele protects against alcohol-relatedbirthdefectsamongAfrican-Americans. J Pharmacol Exp Ther 283:1095-1101.

-Middaugh LD, Randall CL, Favara JP (1988): Prenatal ethanol exposure in C57 mice: effects on pregnancy and offspring development. Neurotoxicol Teratol 10:175-180.

Missouri Department of Mental Health, Division of Alcohol, and Drug Abuse (1994): Fetal alcohol syndrome. http://www.well. com/user/woa/fsfas.htm (accessed August 7, 2009).

-Moreland N, la Grange L, Montoya R (2002): Impact of in utero exposure to $\mathrm{EtOH}$ on corpus callosum development and paw preference in rats: protective effects of silymarin. BMC Complement Altern Med 2:10.
Mothes HK, Opitz B, Werner R, Clausing P (1996): Effects of prenatal ethanol exposure and early experience on home-cage and open-field activity in mice. Neurotoxicol Teratol 18:59-65.

Niemela O, Israel Y, Mizozi Y, Fukunaga T, Eriksson CG (1990): Hemoglobin-acetaldehyde adducts in human volunteers following acute ethanol ingestion. Alcohol Clin Exp Res 14:838-841.

Nyström M, Peräsalo J, Salaspuro M (1992): Carbohydrate-deficient transferrin (CDT) in serum as a possible indicator of heavy drinking in young university students. Alcohol Clin Exp Res 16:93-97.

-Peng Y, Kwok KH, Yang P-H, Ng SS, Liu J, Wong OJ, He ML, Kung HF, Lin MC (2005): Ascorbic acid inhibits ROS production, NF- $\mathrm{B}$ activation and prevents ethanol-induced growth retardation and microencephaly. Neuropharmacology 48:426-434.

Randall CL, Taylor WJ, Walker DW (1977): Ethanol-induced malformations in mice. Alco hol Clin Exp Res 1:219-224.

Reimers MJ, la Du JK, Periera CB, Giovanini J, Tanguay RL (2006): Ethanol-dependent toxicity in zebrafish is partially attenuated by antioxidants. Neurotoxicol Teratol 28:497508.

Reynaud M, Schellenberg F, Loisquex-Meunier MN, Schwan R, Maradeix B, Planche F (2000): Objective diagnosis of alcohol abuse: compared values of carbohydrate-deficient transferrin (CDT), gamma-glutamyltransferase (GGT), and mean corpuscular volume (MCV). Alcohol Clin Exp Res 24:1414-1419.

Roberson R, Cameroni I, Toso L, Abebe D, Bissel S, Spong CY (2009): Alterations in phosphorylated cyclic adenosine monophosphate response element of binding protein activity: a pathway for fetal alcohol syndrome-related neurotoxicity. Am J Obstet Gynecol 200:193.e1-193.e5.

Sari CY, Zhou FC (2004): Prenatal alcohol exposure causes long-term serotonin neuron deficit in mice. Alcohol Clin Exp Res 28:941-948.

Scanga SE, Ruel L, Binari RC, Snow B, Stambolic V, Bouchard D, et al (2000): The conserved PI3'K/PTEN/Akt signaling pathway regulates both cell size and survival in Drosophila. Oncogene 19:3971-3977.

Scita G, Tenca P, Frittoli E, Tocchetti A, Innocenti M, Giardina G, et al (2000): Signaling from Ras to Rac and beyond: not just a matter of GEFs. EMBO J 19:2393-2398.

Singh AK, Gupta S, Jiang Y, Younus M, Ramzan $M$ (2009): In vitro neurogenesis from neural progenitor cells isolated from the hippocampus region of the brain of adult rats exposed to ethanol during early development through their alcohol-drinking mothers. Alcohol Alcohol 44:185-198.
Spong CY, Abebe DT, Gozes I, Brenneman DE, Hill JM (2001): Prevention of fetal demise and growth restriction in a mouse model of fetal alcohol syndrome. J Pharmacol Exp Ther 297:774-779.

Stoler JM, Huntington KS, Peterson CM, Peterson KP, Daniel P, Aboagye KK, Lieberman E, Ryan L, Holmes LB (1998): The prenatal detection of significant alcohol exposure with maternal blood markers. J Pediatr 133:346352.

Streissguth AP, Bookstein FL, Barr HM, Sampson PD, O’Malley K, Young JK (2004): Risk factors for adverse life outcomes in fetal alcohol syndrome and fetal alcohol effects. J Dev Behav Pediatr 25:228-238.

-Suvarna N, Borgland SL, Wang J, Phamluong K, Auberson YP, Bonci A, Ron D (2005): Ethanol alters trafficking and functional $N$ methyl-D-aspartate receptor NR2 subunit ratio via H-Ras. J Biol Chem 280:3145031459.

Swayze VW, Johnson VP, Hanson JW, Piven J, Sato Y, Giedd JN, Mosnik D, Andreasen NC (1997): Magnetic resonance imaging of brain anomalies in fetal alcohol syndrome. Pediatrics 99:232-240.

Vaillant C, Didier-Bazes M, Hutter A, Belin MF, Thomasset N (1999): Spatiotemporal expression patterns of metalloproteinases and their inhibitors in the postnatal developing rat cerebellum. J Neurosci 19:4994-5004.

-Vangipuram SD, Grever WE, Parker GC, Lyman WD (2008): Ethanol increases fetal human neurosphere size and alters adhesion molecule gene expression. Alcohol Clin Exp Res 32:339-347

-Verdu J, Buratovich MA, Wilder EL, Birnbaum MJ (1999): Cell-autonomous regulation of cell and organ growth in Drosophila by Akt/ PKB. Nat Cell Biol 1:500-506.

-Wang LL, Zhang Z, Li Q, Yang R, Pei X, Xu Y, Wang J, Zhou SF, Li Y (2009): Ethanol exposure induces differential microRNA and target gene expression and teratogenic effects which can be suppressed by folic acid supplementation. Hum Reprod 24:562-579.

-Wexler EM, Paucer A, Kornblum HI, Plamer TD, Geschwind DH (2009): Endogenous Wnt signaling maintains neural progenitor cell potency. Stem Cells 27:1130-1141.

Winn LM, Wells PG (2002): Evidence for Rasdependent signal transduction in phenytoin teratogenicity. Toxicol Appl Pharmacol 84: 144-152.

Zhou FC, Fang Y, Goodlett C (2008): Peptidergic agonists of activity-dependent neurotrophic factor protect against prenatal alcohol-induced neural tube defects and serotonin neuron loss. Alcohol Clin Exp Res 32:13611371.

-Zhou FC, Sari Y, Li TK, Goodlett C, Azmitia EC (2002): Deviations in brain early serotonergic development as a result of fetal alcohol exposure. Neurotox Res 4:337-342. 